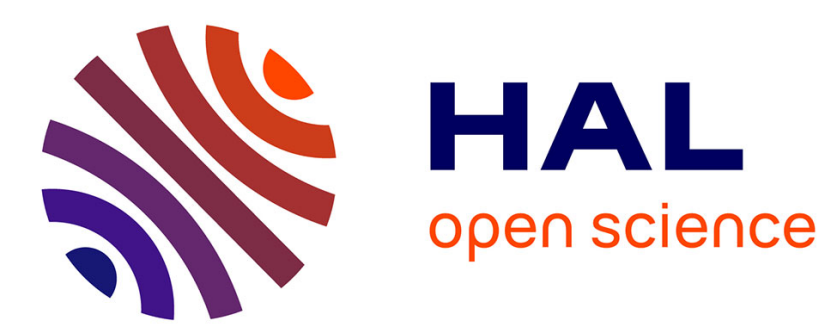

\title{
Seasonal patterns in species diversity across biomes
} Jarad P Mellard, Pauline Audoye, Michel Loreau

\section{To cite this version:}

Jarad P Mellard, Pauline Audoye, Michel Loreau. Seasonal patterns in species diversity across biomes. Ecology, 2019, 100 (4), pp.e02627. 10.1002/ecy.2627 . hal-02350606

\section{HAL Id: hal-02350606 https://hal.science/hal-02350606}

Submitted on 25 Nov 2020

HAL is a multi-disciplinary open access archive for the deposit and dissemination of scientific research documents, whether they are published or not. The documents may come from teaching and research institutions in France or abroad, or from public or private research centers.
L'archive ouverte pluridisciplinaire HAL, est destinée au dépôt et à la diffusion de documents scientifiques de niveau recherche, publiés ou non, émanant des établissements d'enseignement et de recherche français ou étrangers, des laboratoires publics ou privés. 


\title{
Seasonal patterns in species diversity across biomes
}

\author{
Jarad P. Mellard, ${ }^{1,2}$ Pauline Audoye, and Michel Loreau \\ Center for Biodiversity Theory and Modelling, Moulis 09200 France
}

Citation: Mellard, J. P., P. Audoye, and M. Loreau. 2019. Seasonal patterns in species diversity across biomes. Ecology 100(4):e02627. 10.1002/ecy.2627

\begin{abstract}
A conspicuous season-diversity relationship (SDR) can be seen in seasonal environments, often with a defined peak in active species diversity in the growing season. We ask is this a general pattern and are other patterns possible? In addition, we ask what is the ultimate cause of this pattern and can we understand it using existing ecological theory? To accomplish this task, we assembled a global database on changes in species diversity through time in seasonal environments for different taxa and habitats and also conducted a modeling study in an attempt to replicate observed patterns. Our global database includes terrestrial and aquatic habitats, temperate, tropical, and polar environments, and taxa from disparate groups including vertebrates, insects, and plankton. We constructed nine alternative models that vary in assumptions on type of seasonal forcing, responses to that forcing, species niches, and types of species interactions. We found that most guilds of species exhibit a repeatable SDR across years. For north temperate ecosystems, active species diversity generally peaks mid-year. The peak for a guild is generally more pronounced in terrestrial habitats than aquatic habitats and more pronounced in temperate and polar regions than the tropics. We now have evidence that at least several different habitat and taxa types are likely to have multiple peaks in diversity in a year, for example, guilds of both aquatic microbes and desert vertebrates can show a bimodal or multimodal SDR. We compared all nine candidate models in their ability to explain the patterns and match their assumptions to the data. Some performed considerably better than others in being able to match the different patterns. We conclude that a model that includes both temperature niches and environmental feedbacks is necessary to explain the different SDRs. We use such a model to make predictions about how the SDR could be impacted by climate change. More effort should be put into documenting and understanding baseline seasonal patterns in diversity in order to predict future responses to global change.
\end{abstract}

Key words: biodiversity; environmental forcing; feedbacks; seasonal; species interactions; species richness; temporal niche; thermal niche.

\section{INTRODUCTION}

Temporal patterns in biodiversity, in contrast to spatial patterns, have received less attention in ecology (Chesson et al. 2004, White et al. 2006, Usinowicz et al. 2017). However, phenology has long been a focus, with increased efforts recently on how phenologies of species are responding to global change (Cohen et al. 2018, Kharouba et al. 2018). Theoretical research in phenology has largely focused on one or perhaps two

Manuscript received 31 July 2018; revised 21 November 2018; accepted 2 January 2019. Corresponding Editor: Helmut Hillebrand.

${ }^{1}$ Present address: Department of Arctic and Marine Biology, UiT The Arctic University of Norway, Tromsø 9037 Norway.

${ }^{2}$ E-mail: jarad.p.mellard@uit.no interacting species at a time (Revilla et al. 2014; but see Encinas-Viso et al. 2012, Revilla et al. 2015) without explicit links to ecosystem functioning, which, may be impacted if species diversity changes due to the phenology of the entire community (Loreau 2010).

In 1943, C. B. Williams showed that a conspicuous season-diversity relationship (SDR) can be seen in seasonal environments, with active species diversity of macrolepidopterans peaking in mid-Summer each year (Fisher et al. 1943, Magurran 2008). Active species diversity is a measure of which species are currently active in biological processes such as metabolism, growth, and reproduction as detected in the ecosystem by traditional taxon-specific survey methods, for example, an insect captured in a trap or a plant flowering. Exploration of the SDR and hypothesized mechanisms 
have received some attention (Rosenzweig 1995), and perhaps the best recent empirical evidence of the SDR comes from grassland plant communities (Craine et al. 2012) where abiotic factors are hypothesized to set the beginning and end of the growing season while biotic factors such as competition may set the phenological strategy of species during the growing season (Wolkovich and Cleland 2014). In mesic habitats, limiting resources such as water appear to play a role in the middle of the growing season (Aldridge et al. 2011), although experimental warming on its own can drive mid-season patterns and create a midseason gap with no impact of precipitation (Sherry et al. 2007). Regardless, asynchrony and the phenological strategy of individual species including possible bimodality or multiple generations during the year (Shaltout and El Fahar 1991) are suspected to be important mechanisms in plant communities. Needed still is a broader understanding of what may be the same processes that are operating in different types of ecosystems with the eventual goal of identifying the mechanisms responsible to understand temporal heterogeneity in ecosystem functioning.

In order to make predictions on how biodiversity will respond to further global change, it is necessary to document and attempt to understand current patterns in biodiversity. We examine the repeated seasonal assembly of communities where phenologies play a key role. Empirically, we ask what type of SDR do we observe? Using theory, we ask what may be responsible for this pattern and what causes the differences in the pattern, specifically within and between habitats and functional guilds of species? We are primarily concerned with the ultimate causes of the phenological patterns across different types of communities, not the proximate cues that some organisms may use during their phenology. Our hypothesis is that the relative balance of abiotic-limited growth (resources, temperature) (Cushing 1990) and biotic-limited growth (species interactions) determines the phenological strategy of different species and the resultant diversity patterns of guilds. The degree of abiotic and biotic limitation likely varies across ecosystems, thus, it may be possible to observe different SDRs across different types of taxa and ecosystems.

Although numerous studies have looked at the SDR for a particular taxonomic group, we are not aware of any study that has attempted to put these patterns together to compare and synthesize what we know about seasonal patterns across taxonomic groups of species and habitat types. We assemble a database, for what we believe to be the first time, to examine the pattern across biomes in order to compare and look for generality (Rosenzweig 1995). Furthermore, although some conceptual models may exist, we provide a mathematical modeling framework in an attempt to explain the ultimate causes of this pattern, and that may link these disparate systems from around the world to common underlying biological mechanisms. We relate how individuals respond to seasonal variation in growing conditions, which in turn lead to population responses in resources availability, and finally to community-level patterns in active species diversity.

We expect high active species diversity to occur primarily during the growing season (Klausmeier 2010), however, it is currently unclear if and when in the growing season, species diversity should peak. For example, during a growing season, species with different timings and durations of a life stage (for life stages shorter or longer than a growing season) may not be in synchrony with one another. Thus the temporal distribution of different species may be evenly spread over the growing season or more temporally aggregated and thus have a peak(s) in species diversity. If a peak forms, we may expect species diversity to peak at the beginning of the growing season when resources are high if all species have a chance to grow. Alternatively, species diversity could peak at the middle of the growing season, for example if carrying capacity is temporally varying with the season due to external forcing or when species have the most overlap in their phenologies. Diversity could also peak at the end of a growing season if abiotic conditions slows growth or as species steadily accumulate to fill niche space or alter their environment through interactions in a diversity begets diversity scenario.

We find several consistent, repeatable patterns across habitat and taxa types. This suggests a common seasonal forcing and similar ecological responses to that forcing. Our mathematical modeling uncovers a class of models that share features and points to different temporal (temperature) niches for species and seasonal forcing as potential universal mechanisms, since models with these ingredients are better able to replicate the observed patterns. In addition, we uncovered some less documented features of the SDR such as the commonness of bimodality in distributions of species and communities during the year. We provide some guidance on future research directions in order to further pinpoint the candidate processes, however, eventually the active seasonal diversity should be linked to measures of ecosystem fluxes.

\section{Methods}

\section{Data}

We compiled data on species diversity through time in different habitat types in order to look for SDR patterns throughout the world. We divided the data into three characteristic climates of the world based on latitude: tropical $\left(0^{\circ}-23.4\right)$, temperate $\left(>23.4^{\circ}-66.5^{\circ}\right)$, and polar $\left(>66.5^{\circ}\right.$ ) climates (Dillon et al. 2010). We classified subtropics as temperate climate. We further divided the data into different habitat types and guilds of species within these climates.

We searched for data published online, using Google scholar with the key words: seasonal or phenology combined with abundance or species richness or species diversity combined with pattern combined with different climates, habitats, terrestrial or aquatic, and types of taxa. 
TABle 1. Summary of model assumptions.

\begin{tabular}{|c|c|c|c|c|c|c|c|c|c|}
\hline Model & $\begin{array}{l}\text { Growth } \\
\text { function }\end{array}$ & Forcing & Sp interact & Unimodal? & Bimodal? & Multimodal? & Turnover? & $\begin{array}{l}\text { Peak } \\
\text { nsp? }\end{array}$ & Ind sp? \\
\hline 1. No regulation & $g=$ constant & Binary & None & - & - & - & - & - & - \\
\hline $\begin{array}{l}\text { 2. Different } \\
\mu \text { 's Logistic }\end{array}$ & $g=f(N)$ & Binary & None & Yes & - & - & - & High & Unimodal \\
\hline 3. $R$-competition & $g=f(R)$ & Binary & Indirect & Yes & - & - & Yes & Low & Unimodal \\
\hline 4. Facilitation & $g=f\left(R, N_{n+1}\right)$ & Binary & $\begin{array}{l}\text { Direct/ } \\
\text { indirect }\end{array}$ & Yes & - & - & Yes & Low & Unimodal \\
\hline $\begin{array}{l}\text { 5. Prey Dif. } \\
\mu \text { 's Logistic }\end{array}$ & $g_{N}=f(N, P)$ & Binary & Direct & Yes & - & - & - & High & Unimodal \\
\hline Predator & $g_{p}=f(N)$ & Binary & Direct & Yes & - & - & - & High & Unimodal \\
\hline 6. $T$-dep Logistic & $g=f(T, N)$ & Sin & None & Yes & Yes & - & Yes & High & Bimodal \\
\hline $\begin{array}{l}\text { 7. Prey } T \text {-dep } \\
\text { Logistic }\end{array}$ & $g_{N}=f(T, N, P)$ & Sin & Direct & Yes & Yes & - & Yes & High & Bimodal \\
\hline Predator & $g_{p}=f(N)$ & & Direct & Yes & Yes & - & Yes & Medium & Unimodal \\
\hline $\begin{array}{l}\text { 8. Shared } \\
\text { preferences }\end{array}$ & $g=f(T, R)$ & Sin & Indirect & Yes & Yes & Yes & Yes & Medium & Multimodal \\
\hline $\begin{array}{l}\text { 9. } T \text {-dep } \\
R \text {-competition }\end{array}$ & $g=f(T, R)$ & $\operatorname{Sin}$ & Indirect & Yes & Yes & Yes & Yes & Medium & Bimodal \\
\hline
\end{tabular}

Notes: Growth function specifies what factors growth depends on, $N$ is population density, $R$ is resource quantity, $P$ is predator, $T$ is temperature. Forcing is the type of environmental forcing, binary is two seasons (a growing season and a bad season), and sin is sinusoidal temperature forcing. Sp interact is type of species interaction, direct (facilitation or predator-prey) or indirect (through shared resources). Unimodal, bimodal, and multimodal are the resultant shapes of the season-diversity realtionship (SDR). Turnover is whether species turnover occurs throughout the season. Peak nsp is the number of species that results from the model assumptions. Ind $\mathrm{sp}$ is the shape of biomass distribution observed in a year for each species. Cells with dashes mean that model was not able to match that observation from the data. See Appendix S1 for detailed description of models.

As much as possible, we tried to obtain raw data from the original authors. If the data was not available, we extracted the data directly from published figures using Web Plot Digitizer. We also obtained data from online databases such as Dryad and Long Term Ecological Research (LTER). ${ }^{1}$ We distinguished between two types of data: (1) The abundances of species, the number of individuals of each species found during a time and (2) Species richness, the number of species found during a time. Temporal resolution varied so we include only data for which we had a minimum of one year with at least seven months represented (six months for polar data sets) in the data and at least monthly sampling resolution in order to have results for all seasons. Most data sets had at least 10-12 months. For consistency across taxa, we included only data sets that identified taxa down to the species level (or at least genus level for some hard to identify taxa such as phytoplankton) and had a minimum of six species in the community identified (five species for polar data sets).

We were able to obtain and analyze a total of 41 data sets: 25 temperate (13 terrestrial, 12 aquatic), 10 tropical ( 8 terrestrial, 2 aquatic), and 6 polar (1 terrestrial, 4 aquatic) guilds (Appendix S1: Tables S1, S2). We quantitatively analyzed the SDR by finding the numerical maximum in species diversity to identify the peak. In some cases, the same maximum number of species can be found multiple times during the year, so we kept all maxima in order to not lose information. We standardized species diversity by the maximum diversity, dividing each species richness value by the maximum value of

${ }^{1}$ LTER (1989-1995); https://jornada.nmsu.edu/lter/data/animal species richness found for a given guild. We fit a spline in $\mathrm{R}$ version 3.3.2 using the function smooth.spline with degrees of freedom equal to $2+\sqrt{n}$, where $n$ is number of data points (Weithoff et al. 2015). For the overall spline that contains multiple data sets, we set the degrees of freedom equal to $n$. Many of the data sets contained only a single year and since there is there is no agreed upon test of bimodality (Aldridge et al. 2011), we present the raw data following previous studies.

\section{Theoretical}

The general theoretical framework is presented here and each model is described in detail in Appendix S1 and summarized in Table 1. We build on previous modeling of consumer-resource systems. We define the population size $N_{i}$ of species $i$ to change in time according to,

$$
\frac{d N_{i}}{d t}=f\left(N_{i}\right)=N_{i} g_{i}
$$

where $g_{i}$ is growth rate. Growth rate $g_{i}$ is a function of the max growth rate $\mu\left(x_{i}\right)$ as determined by the speciesspecific trait $x_{i}$. In the case of logistic growth, $g_{i}$ is dependent on population size $N_{i}$, carrying capacity $K_{i}$, and mortality $m_{i}$ of species $i$

$$
g_{i}(x)=\mu\left(x_{i}\right)-\mu\left(x_{i}\right) \frac{N_{i}}{K_{i}}-m_{i} .
$$

Therefore, we do not explicitly model the resource in the case of logistic growth. In the case of resource 
competition, $g_{i}$ is dependent on resource quantity $R$, half saturation constant $k\left(x_{i}\right)$, and mortality $m_{i}$

$$
g_{i}(x)=\mu\left(x_{i}\right) \frac{R}{R+k\left(x_{i}\right)}-m_{i}
$$

The resource is depleted by all populations of species. In a constant environment, the resource quantity $R$ takes the form

$$
R(t)=R_{\mathrm{in}}-\sum_{i=1}^{n} N_{i}
$$

where $R_{\text {in }}$ is resource supply rate and there are $n$ species in the system. This allows us to have an algebraic equation for the resource and mass-balance constraint on the system.

To create a seasonal environment, we use several different types of seasonal forcing equations. For binary environmental forcing (Klausmeier 2010) without resource depletion, we make part of the year have a bad season by setting the growth function $g_{i}$ equal to a small negative value when $t \geq \phi P$, where $P$ is the time period ( $1 \mathrm{yr}=$ $365 \mathrm{~d})$ and $\phi$ is the growth season proportion of the year.

For resource-based forcing, we make part of the year have a bad season by setting $R(t)=0$

$$
\begin{gathered}
R(t)=R_{\text {in }}-\sum_{i=1}^{n} N_{i} \quad \text { for } \quad t<\phi P \\
R(t)=0 \quad \text { for } \quad t \geq \phi P .
\end{gathered}
$$

To model temperature dependence, we give each species a thermal niche that defines the growth rate as a function of temperature and the difference in temperature to the optimal temperature for that species (Appendix S1: Eq. S5, Fig. S11). For seasonal forcing with temperature dependence, we consider temperature to vary sinusoidally on an annual cycle following realistic values, $T=f(\sin (t))$.

We confirmed the stable community outcome using a community assembly approach, allowing many species with traits spread evenly along the trait axis to all grow and compete with one another from a low initial density. We considered the stable attractor, that which occurs over multiple years. We ran numerical simulations for each model using NDSolve in Mathematica version 11 (Wolfram Research, Champaign, IL, USA). We defined a period as one year and used the output from the end of one year as the starting conditions for the next year. We also considered immigration, a small amount of biomass $\left(10^{-6}\right)$ of each species that was allowed to enter the system at the start of the year. We did this to test whether adding a small level of immigration each year for every species changes the patterns, and found the patterns are robust to this assumption. We ran the model until it reached the stable attractor, that is until we observed no further changes in the population sizes at the end of the periods.
The time scale plotted in figures is a year at the stable attractor. For better numerics and speed, we defined an extinction threshold $\left(10^{-100}\right)$, below which a species population equation was set equal to zero in the following year.

The community patterns in species diversity are a result of population-level phenomena in our models. We monitored the biomass of species through time and, if the biomass of a species was above a certain detection threshold, we considered that species as part of the community and counted it in the survey of species diversity present at a given time. This allowed us to generate plots equivalent to the empirical plots. We used very low starting densities for all species and set the detection threshold always at least two orders of magnitude above that. Generally, the threshold we set depended on $R_{\text {in }}$ and number of species $n_{\mathrm{sp}}$, a threshold for example of $R_{\text {in }} / n_{\text {sp }} \geq 1$ with $R_{\text {in }}=100$ and $n_{\text {sp }}=100$. Other parameter values were systematically varied from a range of realistic values. Model specific parameter values are listed in the figure captions of example output from each of the model descriptions. We compared how well models matched data based on both assumptions and outcomes, focusing on the ability of a model to generate the different observed shapes of SDR (unimodal, bimodal, and multimodal), species turnover patterns during the season, the peak number of species that are present, and the shape of biomass distribution for individual species during the season (Table 1).

\section{RESULTS}

\section{Data}

We assembled a global seasonal diversity database by combining 41 published data sets with the goal of uncovering general patterns in live species abundances observed in routine sampling and monitoring of field sites. We found seasonality everywhere we looked (Figs. 1-5, Appendix S1: Figs. S25-S29), even in places not thought to be highly seasonal such as caves and deep-sea environments. However, the SDR in the tropical climate (Fig. 2a, b) was not as clear as in the temperate (Fig. 1). Unfortunately, we were able to find very few data sets for polar climates. All Arctic data came from only station, Nuuk, Greenland (Figs. 2c, d, 5), and we have only one data set from the Antarctic region (Figs. 4d, 5). Furthermore, we have only two data sets from the southern hemisphere temperate region (Fig. 4c), but they appear to show the inverse of the SDR seen in the northern hemisphere region.

Generally, species diversity changed several fold on an annual cycle and showed a unimodal pattern (Fig. 1). Most guilds of species exhibited highly repeatable patterns, showing more intra-annual variation in species diversity than inter-annual variation, also noted by (Fisher et al. 1943). We often, but not always, observed a well-defined peak in diversity for a guild of microbes, insects, plants, or vertebrates. For northern hemisphere 
a

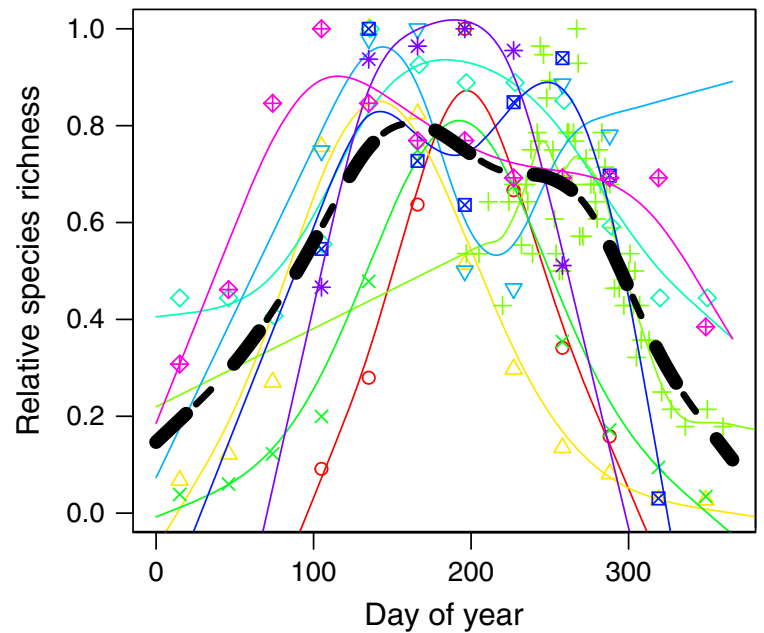

C

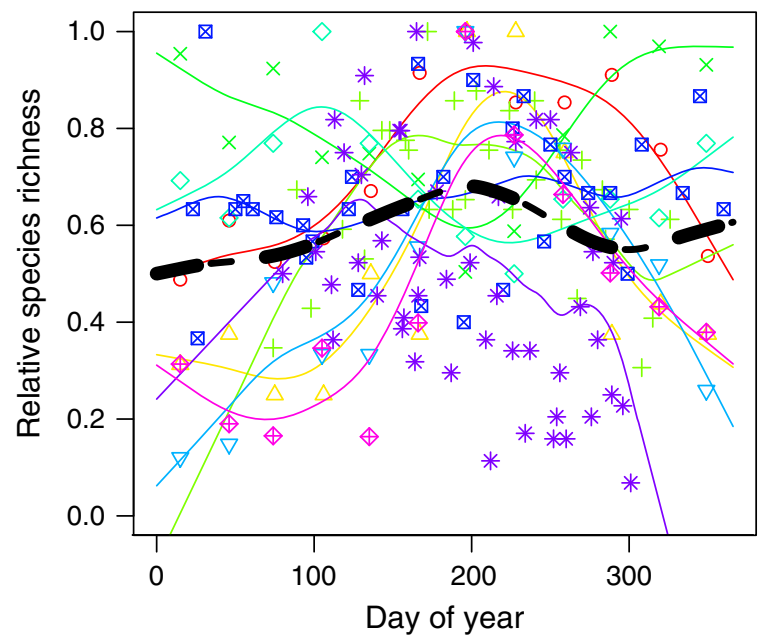

b

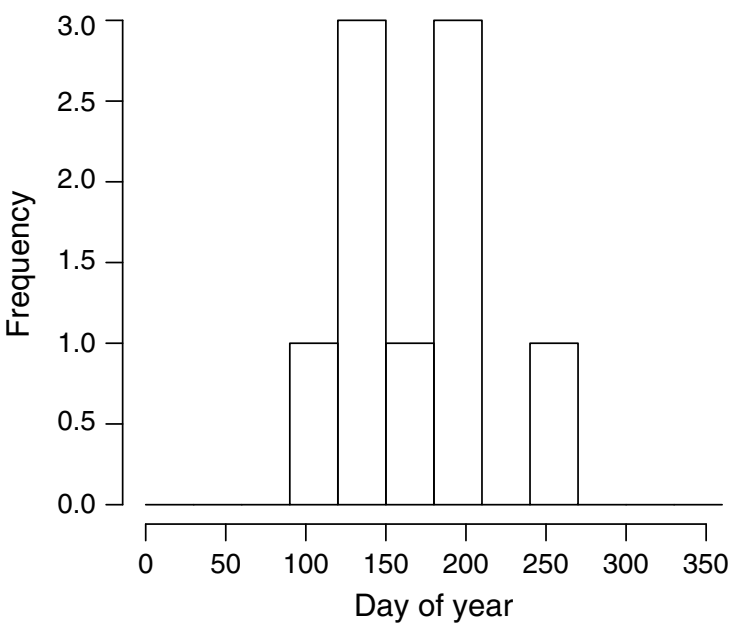

d

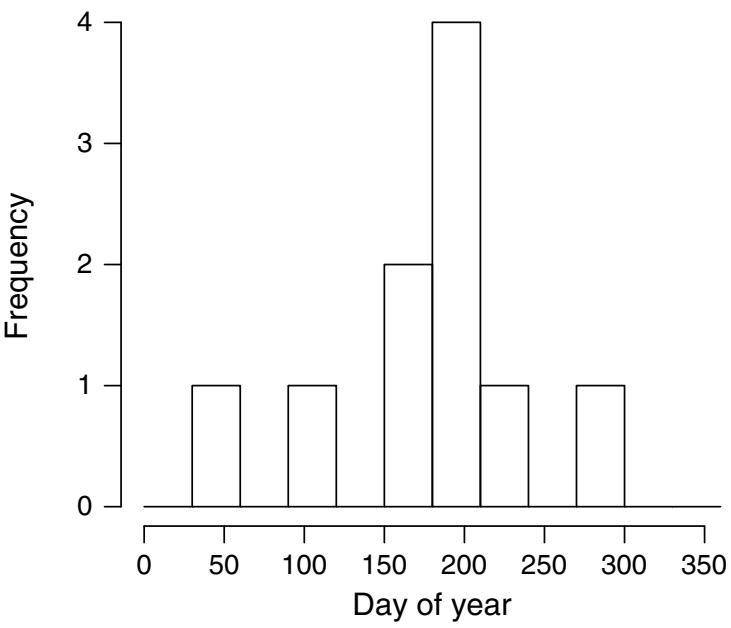

FIG. 1. Species richness in the temperate zone of the northern hemisphere, separated into terrestrial (a,b) and aquatic (c,d) habitats. (a) Species richness and (b) day of maximum species richness in terrestrial ecosystems. (c) Species richness and (d) day of maximum species richness in aquatic ecosystems. Each data point type and color is a different data set with the spline fit line in the same color for that data set. The thick dashed black line is the spline fit for all data sets of the same ecosystem type and region. Data sources for panels a and b are as follows $(n=9)$ ): red hollow circles are macrolepidoptera (Rosenzweig 1995), yellow triangles pointing up are birds (Fogden 1972), light green crosses are birds (Thompson and Willson 1979), green x are lepidoptera (Rosenzweig 1995), blue-green diamonds are birds (Rosenzweig 1995), blue triangles pointing down are insects (Inoue et al. 1990), dark blue squares with $\mathrm{x}$ are flowers (Inoue et al. 1990), purple snowflakes are bees (Oertli et al. 2005), magenta diamonds with crosses are beetles (Krasnov and Ayal 1995). Data sources for panels $\mathrm{c}$ and $\mathrm{d}$ are as follows $(n=9)$ ): red hollow circles are fish (Tremain and Adams 1995), yellow triangles pointing up are fish (Fischer and Eckmann 1997), light green crosses are phytoplankton (Baker and Baker 1981), green x are fish (Claridge et al. 1986), blue-green diamonds are macrobenthos (Whitlatch 1977), blue triangles pointing down are fish (Hoff and Ibara 1977), dark blue squares with x are zooplankton (Primo et al. 2009), purple snowflakes are phytoplankton (Trifonova 1993), magenta diamonds with crosses are phytoplankton (Weithoff et al. 2015).

temperate ecosystems, that peak in diversity was most often mid-year. Among 20 data sets in the northern hemisphere temperate region, 7 had their diversity peak in July and 11 during summer (Appendix S1: Fig. S25, S26). The peak appeared more pronounced in terrestrial habitats (Fig. 1a) than aquatic habitats (Fig. 1b).

Furthermore, species diversity tended to peak midyear but could be shifted to earlier in the year for some northern hemisphere temperate terrestrial systems (e.g. beetles, bees, flowers) (Fig. 1a; Appendix S1: Figs. S27, S28) or later for some aquatic systems (plankton; Fig. 3; Appendix S1: Fig. S29). For example, we observed a very sharp peak earlier in the year for bee diversity and first flowering day for a number of plant species (Appendix S1: Figs. S27, S28). Phytoplankton diversity not only peaked early and late in the growing season around stratification and mixing times, but could also peak in the middle of summer (Fig. 3). 
a

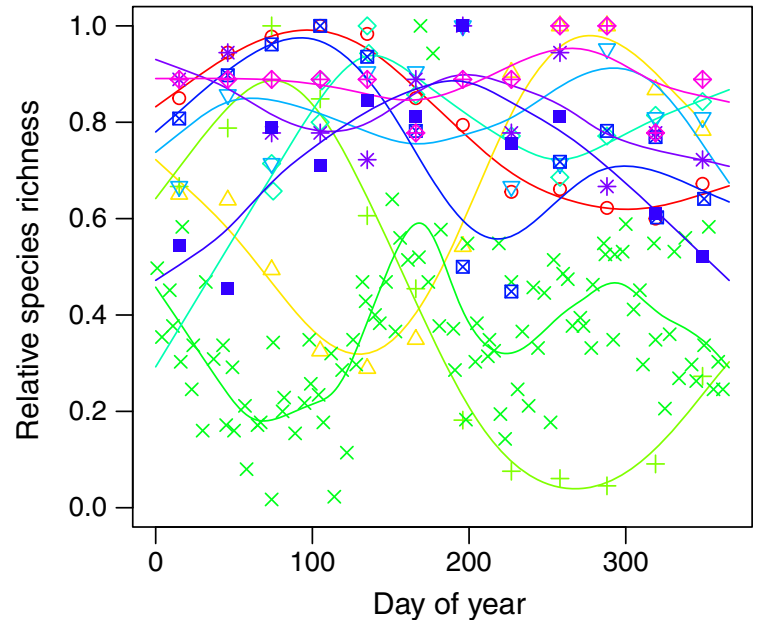

C

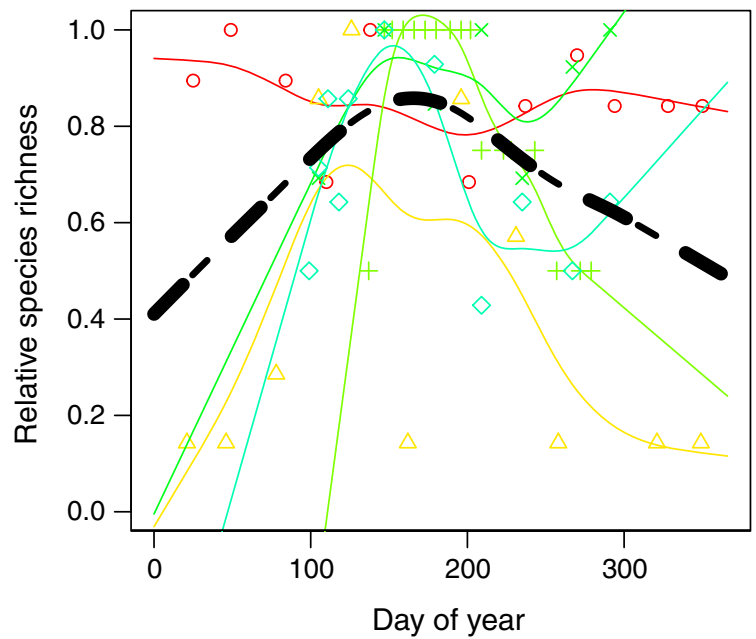

b

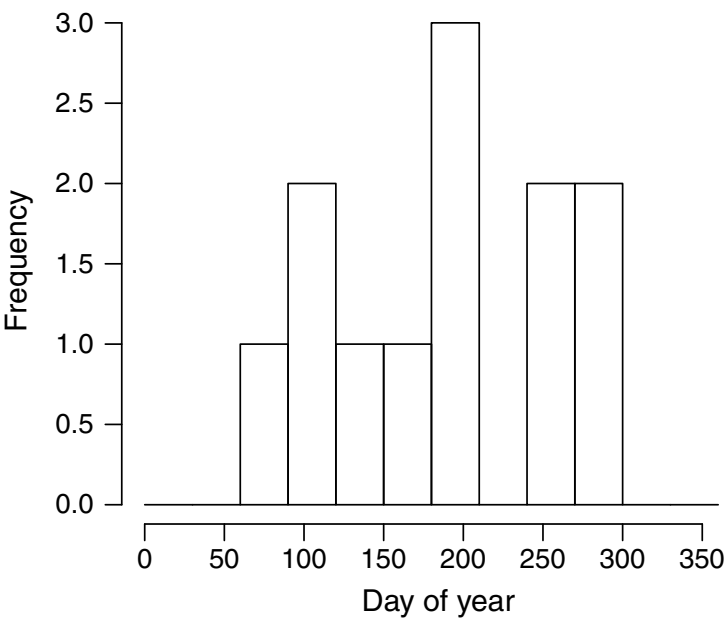

d

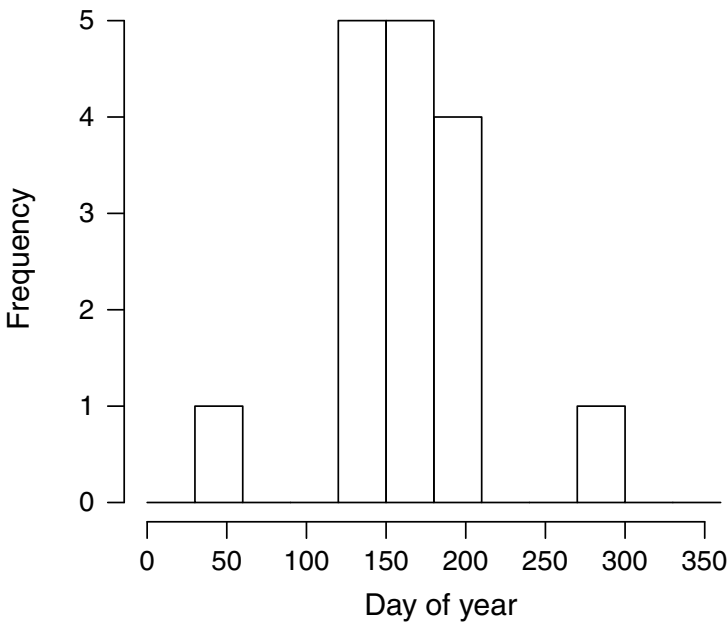

FIG. 2. Species richness in $(a, b)$ the tropics and $(c, d)$ the northern hemisphere polar zone. (a) Species richness, (b) day of maximum species richness in tropical ecosystems, (c) Species richness and (d) day of maximum species richness in northern hemisphere polar ecosystems near Nuuk Greenland. Each data point type and color is a different data set with the spline fit line in the same color for that data set. The thick dashed black line is the spline fit for all data sets of the same ecosystem type and region. Data sources for panels $\mathrm{a}$ and $\mathrm{b}$ are as follows $(n=9)$ ): red hollow circles are flowers (Wright and Calderon 1995), yellow triangles pointing up are butterflies (Tiple and Khurad 2009), light green crosses are birds (Fogden 1972), green x are insects (Denlinger 1980), blue-green diamonds are lepidoptera (Owen 1969), blue triangles pointing down are orchid bees (Ramírez et al. 2015), dark blue squares with $\mathrm{x}$ are fish (Ansari et al. 1995), purple snowflakes are fish (Barletta et al. 2003), magenta diamonds with crosses are earthworms (Tondoh 2006). solid blue squares are butterflies (Devries et al. 1997). Data sources for panels a and b are all from the same year $2010(n=5)$ : red hollow circles are marine zooplankton (GEM, 2018), yellow triangles pointing up are marine fish larvae (GEM, 2018), light green crosses are birds (GEM, 2018), green $x$ are phytoplankton from Lake Badesø (GEM, 2018), blue-green diamonds are zooplankton from Lake Badesø (GEM, 2018).

Although aquatic microbes showed considerable yearto-year variation, patterns emerged when many years were considered. We discovered some guilds have bi- or multi-modal distributions of species diversity in a year and across years (Figs. 3, 4; Appendix S1: Fig. S29). Multiple peaks in species diversity were more likely in aquatic microbes, and also in desert vertebrates, where temperature may play a role by exceeding the limits of some species. In contrast, other non-vertebrate ectotherms often peaked roughly in the middle of the year just before or during the highest temperature. We also discovered some individual species had bimodal abundance distributions in a year, which, may be responsible for the bimodal SDR (Shaltout and El Fahar 1991, Ulrich 2005, Hsieh et al. 2010).

The SDR of phytoplankton in a lake could be different each year (Appendix S1: Figs. S30, S31), thus for any given year, we could not predict the pattern. This 
a

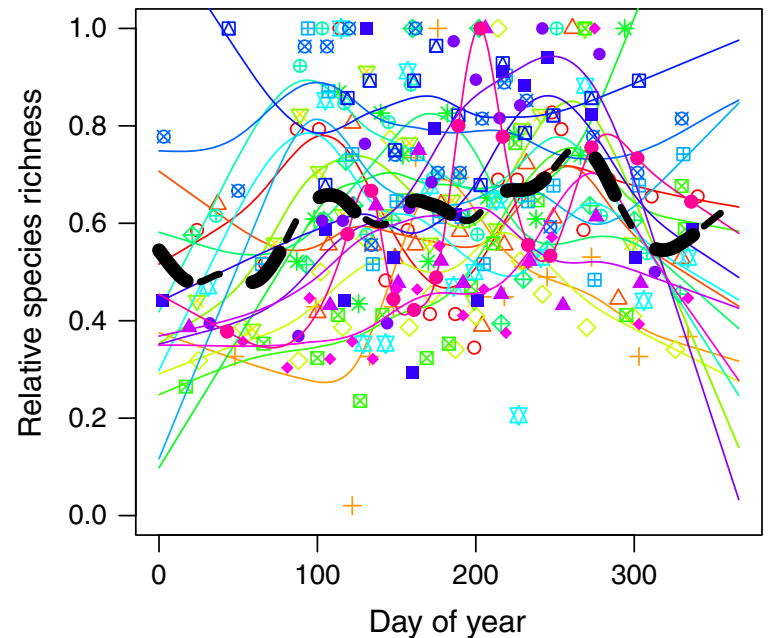

C

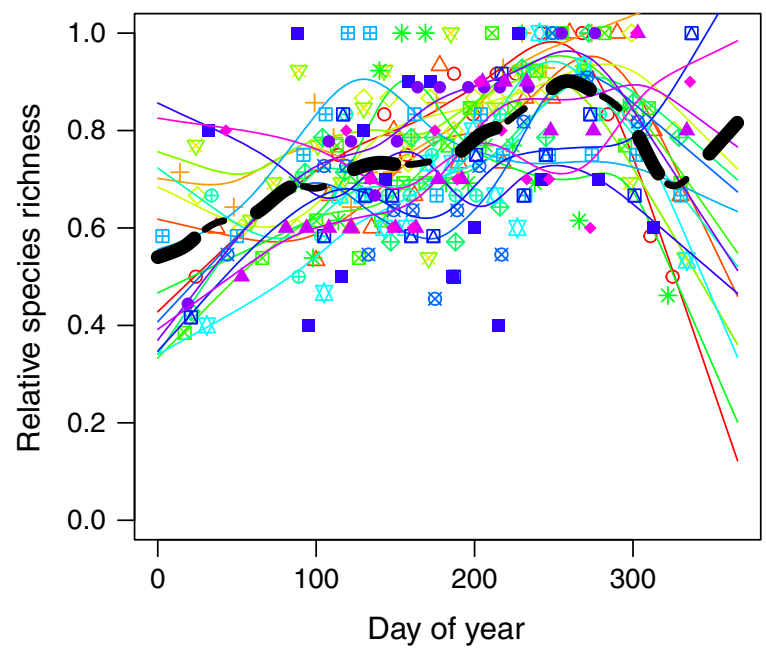

b

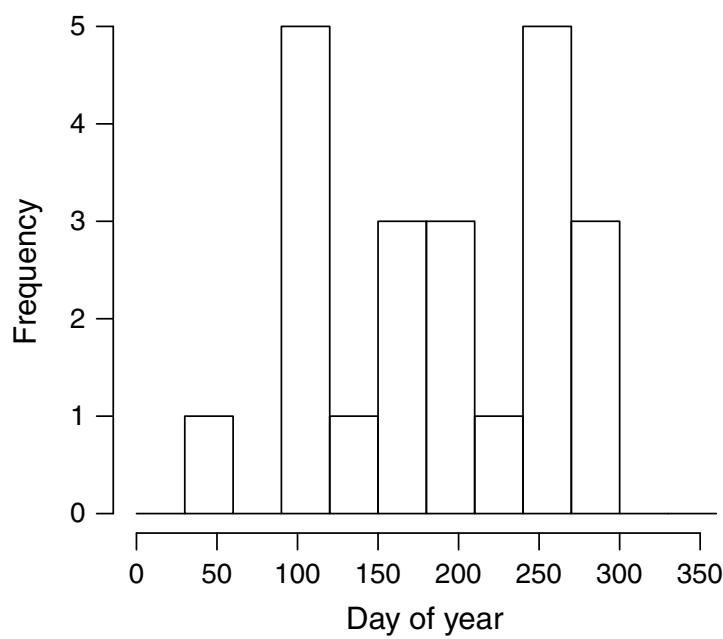

d

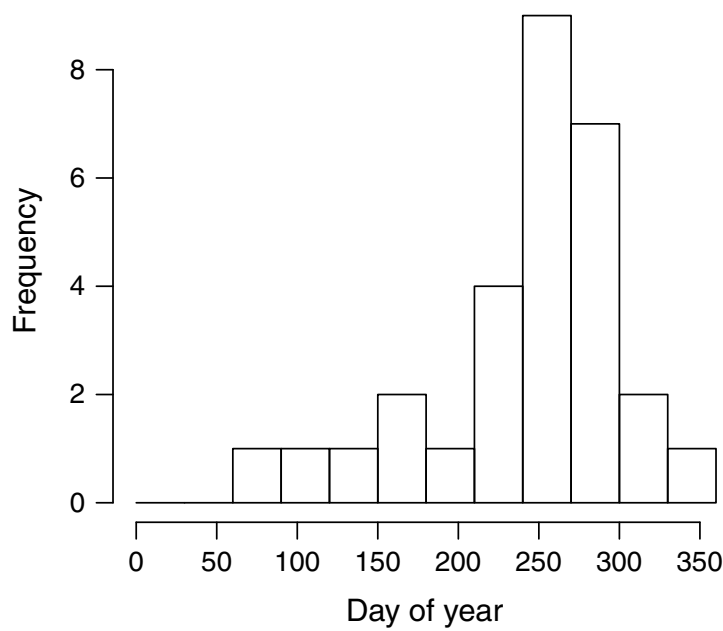

FIG. 3. Examples of inter-annual variability in seasonal diversity from two northern hemisphere temperate species guilds in Lake Mendota: (a,b) phytoplankton and (c,d) zooplankton. (a) Species richness, (b) day of maximum species richness in Lake Mendota phytoplankton, (c) Species richness and (d) day of maximum species richness in Lake Mendota zooplankton. Each data point type and color is a different year with the spline fit line in the same color for that year. The thick dashed black line is the spline fit for all years. Data source is NTLLTER (2011). ${ }^{2}$ Years are 1995-2013 for phytoplankton and 1995-2013 excluding 2006 for zooplankton.

contrasts with the highly repeatable SDR for most other types of organisms and ecosystems. However, different lakes appear to follow the same pattern across years (Appendix S1: Figs. S30, S31), that is there was some synchrony in the shape of SDR, providing evidence of a common external driver. Despite this, the mean maximum species diversity for phytoplankton was shifted by $71 \mathrm{~d}$ between the two lakes, which suggests a role of the local environment. Within a year, we found no concordance between phytoplankton and zooplankton diversity (Irigoien et al. 2004) but across years, we found the highest diversity around day 270 in both phytoplankton and zooplankton according to the overall spline for each

${ }^{2}$ NTLLTER (2011); https://lter.limnology.wisc.edu/data
(Fig. 3; Appendix S1: Fig. S29). Thus the same drivers appear to be operating for both phytoplankton and zooplankton groups but these groups respond somewhat independent of one another.

\section{Model}

We used models to critically examine the hypothesized mechanisms (individual model outcomes are presented in Table 1, Fig. 6 and Appendix S1). From the outset, it was not clear which mechanisms must be included in order to create the observed patterns. Therefore, our modeling addresses a current gap in ecological theory.

Our models consider multiple species in a community, with the population dynamics of each species controlled 
a

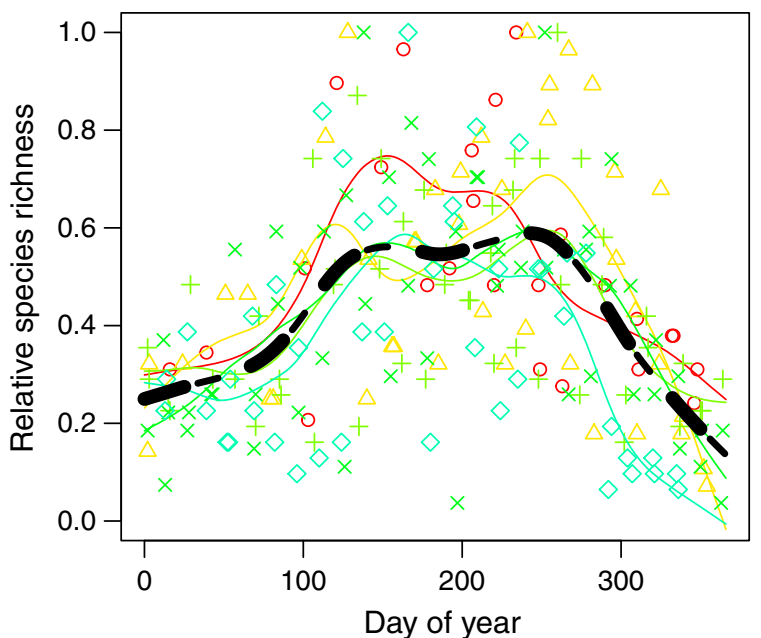

C

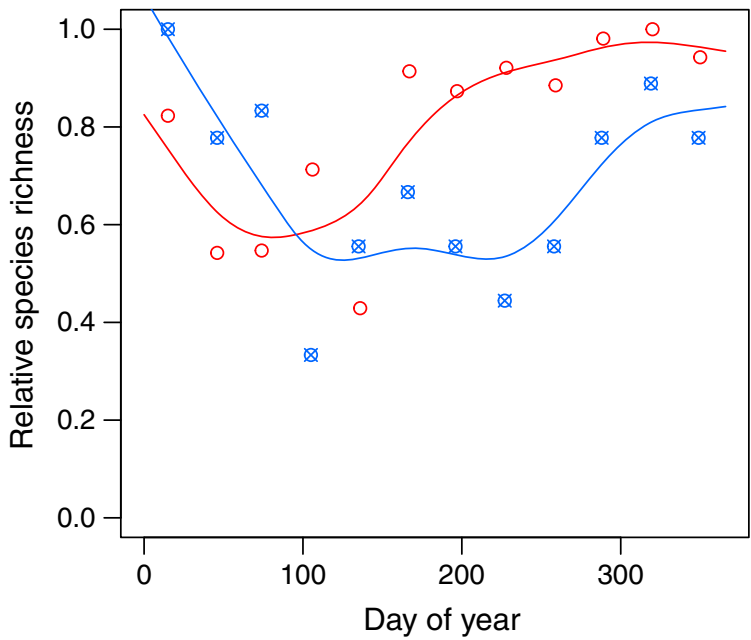

b

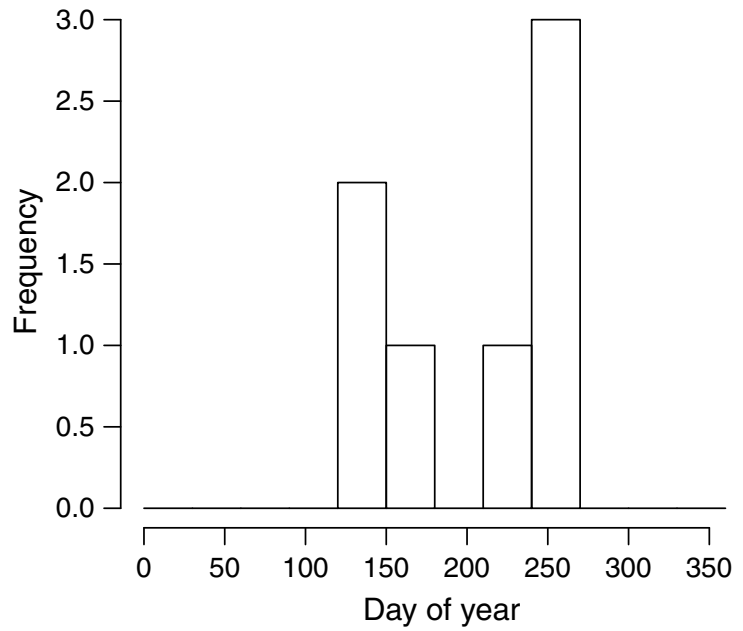

d

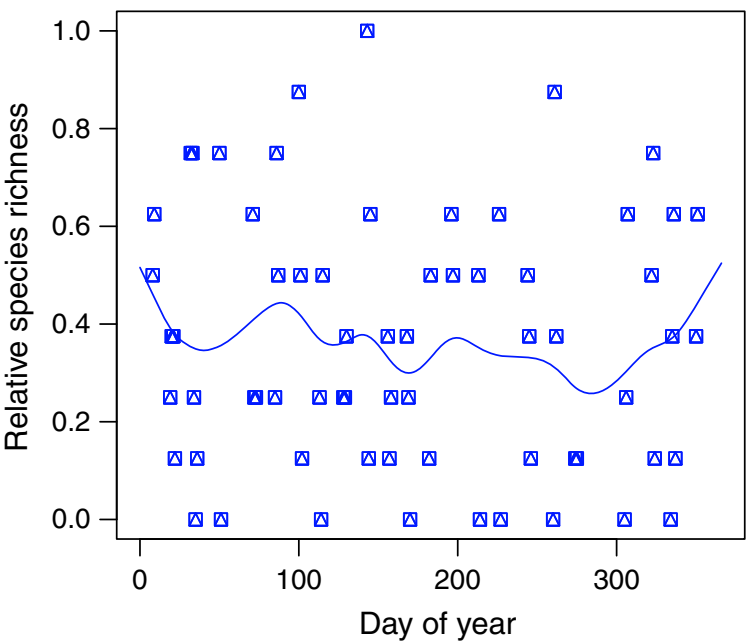

FIG. 4. Example of inter-annual variability in seasonal diversity from $(a, b)$ a northern hemisphere temperate zone vertebrate guild, and our only examples of (c) southern hemisphere temperate zone and (d) southern hemisphere polar zone. (a) Species richness, (b) day of maximum species richness in Chihuahua desert vertebrates, (c) Species richness in a macrobenthos community in an Australian estuary (red hollow circles) and lizards in Argentina (blue circles with x) and (d) Species richness in a zooplankton community in the Antarctic region. Each data point type and color is a different year with the spline fit line in the same color for that year. The thick dashed black line is the spline fit for all years. Data source for panels a and b is LTER (1989-1994). Years are 19901994. Data source for panel c red hollow circles is Rosenzweig (1995), originally from Saenger et al. (1988), and blue circles with $x$ is Fitzgerald et al. (1999). Data source for panel d is (Sewell and Jury 2011).

by its own abundance, forcing of the environment, and feedbacks with the environment, where the environment is defined to include other species (Table 1; Moisan et al. 2002, Klausmeier 2010). Qualitatively, we replicated some of the empirical patterns with many of the models (Fig. 6). This is interesting theoretically, it means minimal assumptions are required to generate some of the patterns, for example an unimodal SDR. In addition, some models were better at replicating a particular pattern. For example, some models better predicted a unimodal pattern ( $R$-competition and Facilitation; Fig. $6 \mathrm{~b}$, c) while some represented diversity better ( $T$-dep
Logistic; Fig. 6e) and some were able to create the different types of patterns (Shared preferences and $T$-dep $R$-competition; Fig. $6 \mathrm{~g}, \mathrm{~h})$. However, only a few models were able to create all of the observed patterns.

We used the following criteria for model selection in order to have some measure of how the different models align with the patterns in the data (Table 1). Eight models can create the observed unimodal SDR (models 2-9). Six models can create opportunities for more than three species to coexist (models 2,5,6,7,8,9). Four models have species turnover (models 6,7,8,9). Those four models can all create a bimodal SDR. We found only two of those 

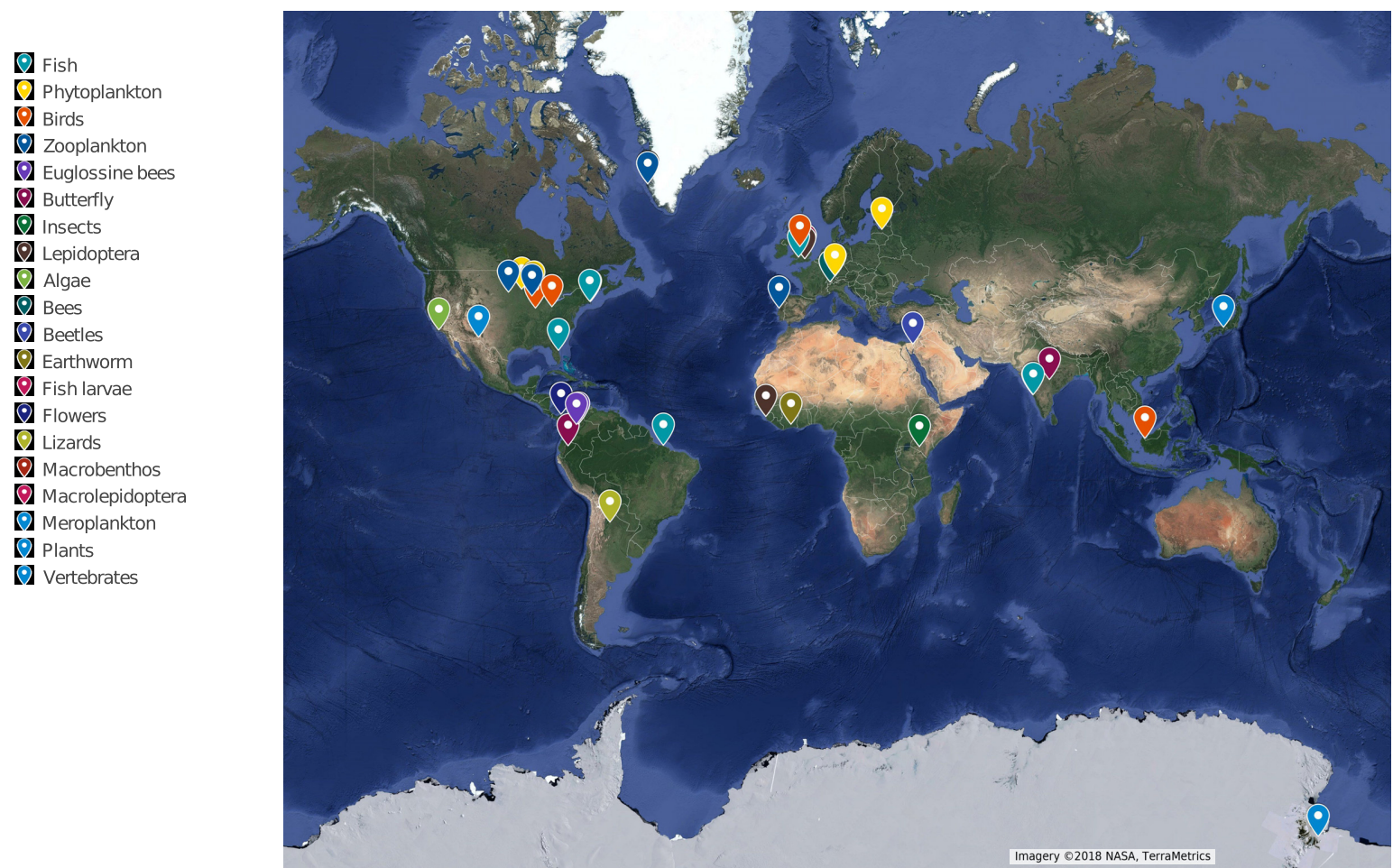

FIG. 5. Geographic map of location of data sets color-coded by taxa. Numbers refer to data set identification number in Appendix S1: Table S2. Note that data set 32, the macrobenthos community in a subtropical estuary in Australia is not shown as we do not have the latitude and longitude coordinates for that location. Map available online at https://www.google.com/maps/d/vie wer?mid=1vF5keeRegS43_59FChklgNBm3AdjMEkf\&usp=sharing

models (models 8 and 9) able to create a multimodal SDR. The shared preferences (Wisheu 1998) model (model 8) is not supported for temperature niches of most taxa in a guild. Thus only one model (model 9), the $T$-dep $R$-competition model, could not only match the different SDR patterns but also many of the assumptions of this model can be verified.

In this $T$-dep $R$-competition model and real communities, species are clustered in niche space (Appendix S1: Fig. S18-S24) (Scheffer and van Nes 2006), interacting, and there are measurable environmental feedbacks such as resource depletion (Appendix S1: Fig. S17) (Wetzel 1975). The well-documented influence of temperature in determining community structure across ecosystems (Sunagawa et al. 2015) provides support for models with temperature niches. We also employ realistic temperature niche widths of species in this model to reflect this evidence (Mellard et al. 2015). Further evidence to support this model include the distributions of individual species in the year. We found that it is common for individual species to have bimodal distributions in the year, both in the data and model (Shaltout and El Fahar 1991, Ulrich 2005, Hsieh et al. 2010).

Using the the $T$-dep $R$-competition model, we were able to generate the different observed species diversity relationships across habitats. We illustrate the capability of the model by forcing it with different lengths and heights of the growing season (Fig. 7). By just changing a few parameters, we generated all SDR patterns observed in the data. Thus we are able to focus on how seasonality controls the SDR instead of species traits, because we have less data about the species traits. Data on seasonality, especially season length and height, can be obtained for everywhere in the world, thus the predictions based on this model could be tested in future work (data available online), https://www.ncdc.noaa.gov/cdoweb/datasets.

\section{Discussion}

A seemingly simple question, when in the year is highest diversity achieved, led to many findings when we assembled the annual pattern across different systems. For example, counteracting factors make it less obvious when we should expect to see the peak in species diversity. Resources may be most abundant at the beginning of the growing season but, depending on how long it takes to grow and deplete, the maximum diversity may not occur until later. Which factors are required to make diversity peak like that observed in the data was not well known. The question of which ecological processes must be modeled to approximate this pattern surprisingly required testing nine different candidate models. This also led us to realize the SDR can take many different 

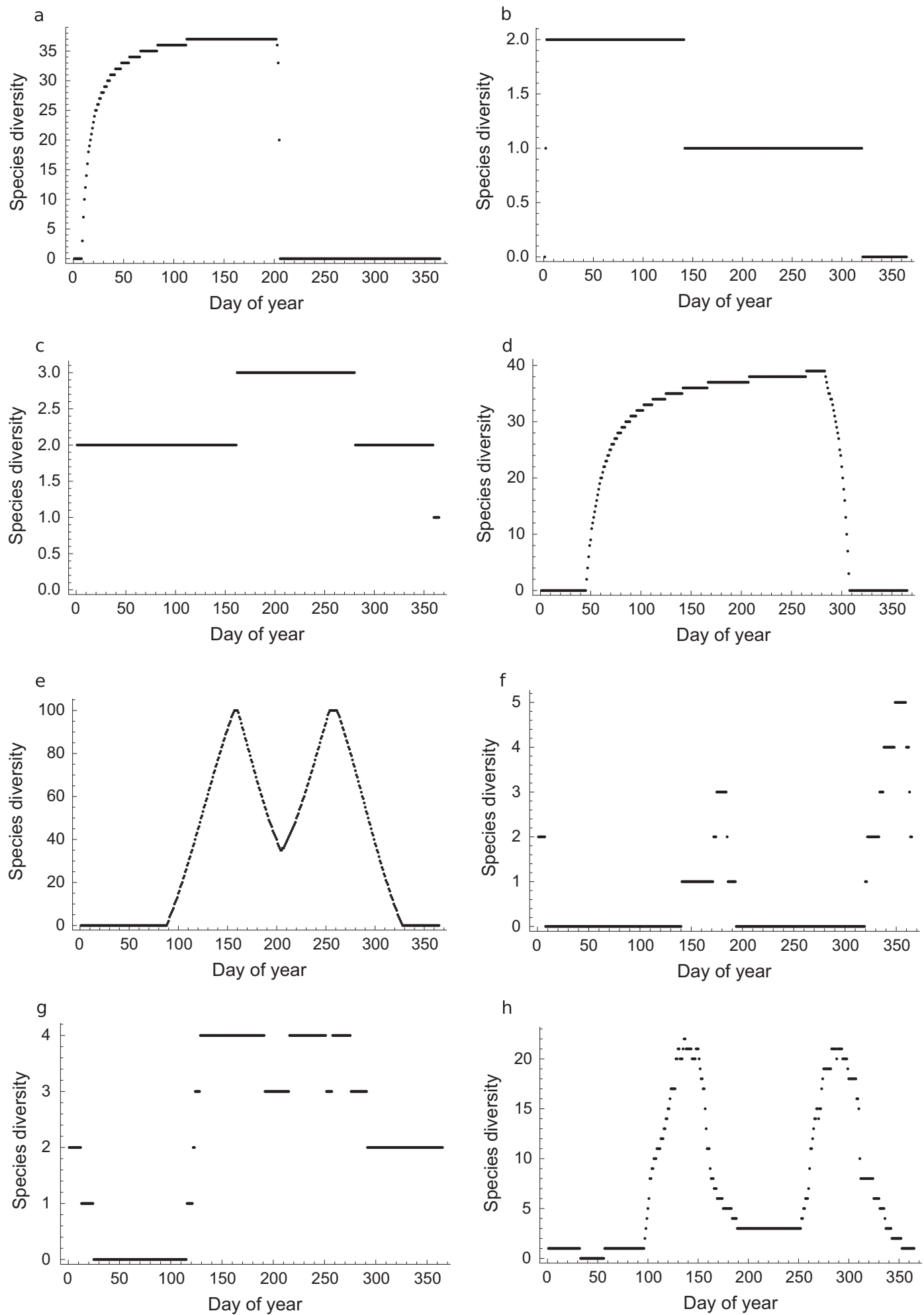

FIG. 6. Season-diversity relationship (SDR) for eight different models listed in Table 1: (a) Model 2. Different $\mu$ 's Logistic, (b) Model 3. $R$-competition, (c) Model 4. Facilitation, (d) Model 5. Prey Different $\mu$ 's Logistic with specialized predators (predator SDR depicted), (e) Model 6. T-dep Logistic, (f) Model 7. Prey T-dep Logistic and specialized predators (predator SDR depicted), (g) Model 8. Shared preferences of $T$-dep $R$-competition, (h) Model 9. $T$-dep $R$-competition. Each plot depicts the number of species present during one year at the stable attractor. Detailed model description, biomass dynamics, prey SDRs for predator-prey models, and parameter values listed with each model in Appendix S1. 

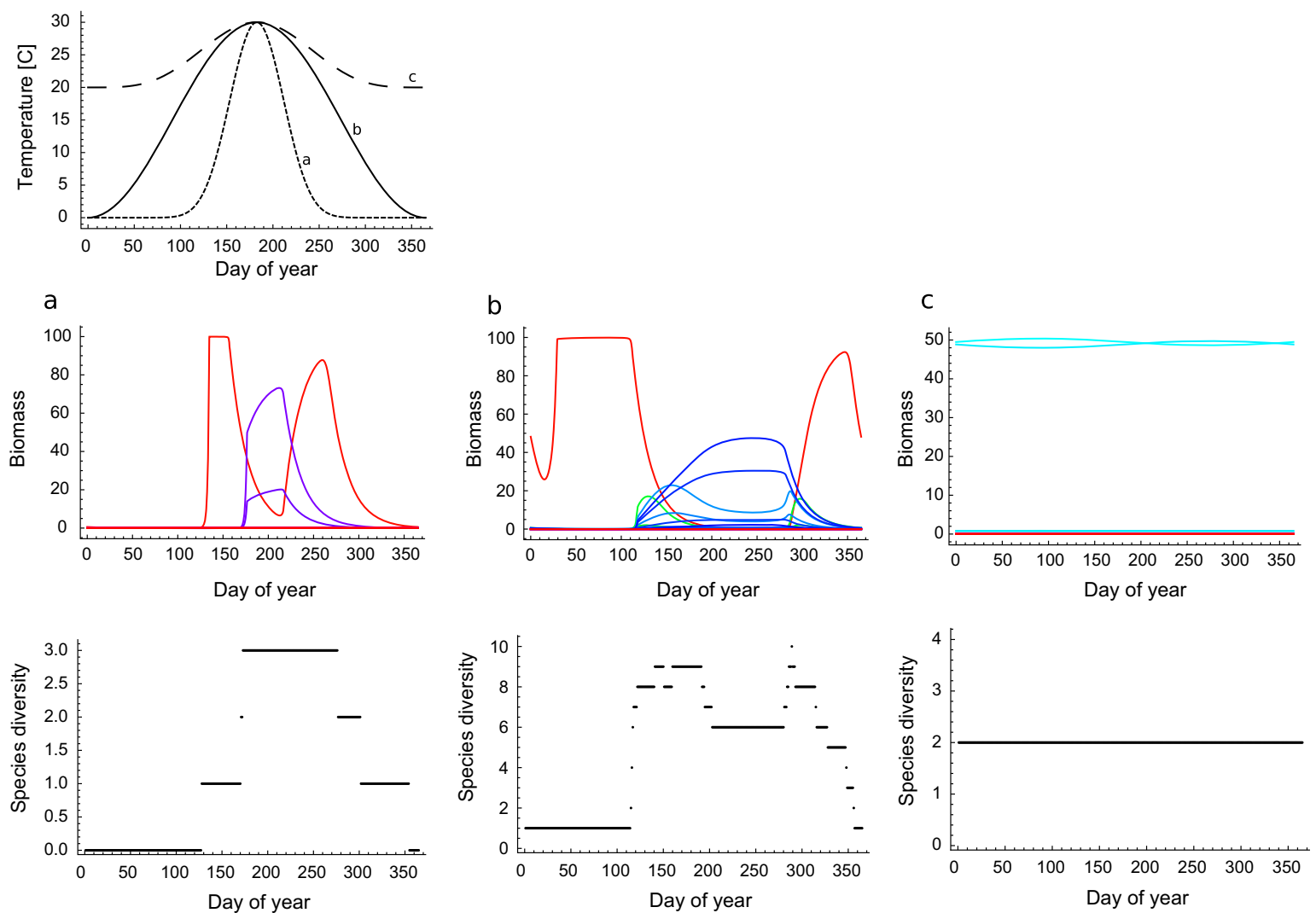

FIG. 7. (Top) Different seasonal forcing temperature curves. Curves with letters a, b, and c create the labeled panels below and different season-diversity relationship (SDRs) in model with temperature-dependent resource competition (model 9). (Middle) Biomass dynamics for 100 species during one year at the stable attractor. Each color is a different species. (Bottom) SDR, number of species present during one year at the stable attractor can be (a) unimodal, (b) bimodal, or (c) constant. Parameter values listed in Appendix S1.

forms, for example relatively constant, unimodal, bimodal, or multimodal.

Our modeling allowed us to consider different hypotheses related to non-equilibrium dynamics and temporal patterns, often neglected while also widely considered to be important. We addressed these both theoretically and empirically. Our modeling illustrates at least three key facets of temporal heterogeneity that should be considered in future biodiversity research and in the broader context of changing communities in time and with global change (1) temperature and resourcebased growth requirements, (2) seasonal variation in temperature and resource availability, and (3) species interactions (competition, facilitation and predator-prey interactions). The greatest number of species flower in the middle of the growing season (Wolkovich and Cleland 2014) in agreement with our findings for many other taxa in terrestrial systems and our modeling. Although this may be no surprise, we are not aware that it has been documented in so many different types of communities before. Furthermore, although we can identify the mean day of year of species diversity peak to be 174 in northern hemisphere temperate systems, we also document much variation around that date. The sources of this variation are (1) among ecosystems; (2) within ecosystems, across years (inter-annual variability); (3) among guilds; (4) within guilds, across ecosystems.

We compiled models that had been used previously to examine seasonal patterns and are well understood theoretically. We also constructed our own models based on hypothesized mechanisms. We systematically varied which biological and ecological processes were included in the models to examine how results depend on different assumptions. We used qualitative model comparison to examine what assumptions are necessary to include to generate the different SDRs, specifically focusing on six metrics listed in Table 1.

Our modeling allows us to hypothesize why some communities decrease in diversity during the year. For example, most communities have a decrease in diversity at some point during or at the end of the year such as the macrolepidoptera in Fig. 1 or the bees in Appendix S1: Fig. S27. Temperature eventually declines in all systems and may be too high in desert vertebrates (Fig. 4) and models 6, 7, 8, and 9 all illustrate this 
mechanism. However, resources can also decline at different points during the season and this is another mechanism that decreases diversity as shown in models 3, 4, 8 , and 9. We hypothesize that both temperature and resources are likely to play a role in lepidopterans (Rosenzweig 1995) and bees (Burkle et al. 2013).

Our models may also help understand gross differences between ecosystem types and latitudes. For example, we observe a fundamental difference between aquatic and terrestrial systems in the amount of seasonal change in diversity. Perhaps terrestrial habitats are subject to stronger seasonal forcing. Our modeling shows we can observe little seasonal change in diversity when species are growing all the time, which can occur for two different reasons. First, in aquatic systems, many species can still grow and persist in the cold, which, we predict to cause a less pronounced SDR. Second, in the tropics, temperature does not change as much so there is reduced seasonality, which, we predict to cause a less pronounced SDR (Fig. 7). The SDR in the tropics may be more strongly driven by the wet and dry seasons, which may differ between sites reducing synchrony across longitude. For example, the butterflies in Tiple and Khurad (2009) and birds in Fogden (1972) appear to be asynchronous (Fig. 2a).

Our modeling uncovers a general mechanism behind the SDR: the interaction between defined temperature niches for individual species with the temperature range of the environment (seasonality). In addition, non-synchrony is important in our model and appears in the data, that is, a progression of species replacement during the growing season, also widely observed in forests, grasslands, and arid ecosystems (Sherry et al. 2007). Longer and stable growing seasons should permit more differentiation between species as has been observed in the tropics where it has been suggested recently that less synchrony may underlie diversity patterns there (Usinowicz et al. 2017). Temperature is one of, if not the primary, control of seasonal dynamics in plant phenological niches (Sherry et al. 2007), although precipitation can also play a role (Wolkovich and Cleland 2014). Precipitation may be considered an especially important form of resource pulse for plants, however, these general mechanisms are not restricted to plants but can be considered for diversity of all lifeforms (Chesson et al. 2004). Since we are concerned with the ultimate causes of the SDR, we consider what may be universal mechanisms operating across different types of taxa. In the end, however, we are merely able to provide testable hypotheses about what drives the universal SDR, specifically, temperature niches, seasonality, and potentially resource depletion operating within the growing season.

Another new insight from our model is we can expect to observe a bimodal SDR if the environmental forcing is not strictly binary, something that has not been addressed before theoretically as far as we know. Bimodality has been shown for phenological activity in weeds in crop systems due to asynchrony with the crop species or multiple generations in a season (Shaltout and El Fahar 1991). In addition, bimodality has been seen in grassland communities due to a mid-season gap that is hypothesized to be a result of resource depletion (Aldridge et al. 2011), especially since demand for resources is high during this reproductive period (Sherry et al. 2007).

In our models, we can get bimodality in the SDR without resource depletion, however, this should be tested with more data because the models with feedbacks appear to show a better match with the different patterns observed across taxa and habitats. Resource depletion likely causes bimodality in montane meadow plant communities. The bimodal SDR has been shown in more mesic habitats, where drought from hotter summer temperatures and earlier snow melt is suspected to be responsible for a mid-summer decline in flowering (Aldridge et al. 2011). In terrestrial plants, bimodality may be caused by resource depletion, but what about other taxa such as animals, where resource depletion may be less obvious? In phytoplankton, bimodality and multimodality may be caused by resource depletion as well, but other density-limiting factors may also play a role such as grazers or parasites, thus a combination of factors may drive the SDR.

We did not include non-uniform spacing of species niches, rather, we let the species niches emerge from the "natural" selection going on in the simulations, perhaps a better representation of nature than anything we could choose. However, if species are manually constrained to be concentrated in niche space then this is another mechanism that can generate or change the form of the SDR, not exclusive to the season length and height. Future research should develop more quantitative tests of the model, especially with explicit links to traits. Ideally, we would have all performance traits related to environmental requirements and impacts measured for every species in the community (Chase and Leibold 2003). For example, the trait parameters in the model include the temperature niche and for some models, the functional responses to resources. If these were measured for each species under controlled experimental conditions (Tilman 1977), we could feed these parameter values into the model and generate predictions for different environmental conditions. These predictions could then be explicitly tested by constructing communities with those species in artificial seasonal environments (Steiner et al. 2009) or in the field under natural conditions. Either way, measuring the environmental parameters (temperature, resources) is also critical in order to match the environment to the predictions and test the role of these factors in driving these patterns (Cohen et al. 2018). We would like to use our verified model to make predictions about other systems in response to global change, an important goal for the future (Sala et al. 2000). However, even without knowing the traits explicitly, by looking at the broad patterns and conducting model comparisons, we developed a better understanding of 
likely mechanisms that drive the seasonal diversity patterns across different communities.

Already, using some of our models, we are able to make predictions on how the SDR will be affected by climate change. The $T$-dep $R$-competition model has realistic environmental parameters we can manipulate, hence provides insights into what can happen under further climate change when we use it as a platform to predict community changes. For example, shifting seasonal forcing curves from a to $\mathrm{b}$ to $\mathrm{c}$ in Fig. 3 represents a predicted climate change scenario with higher mean temperature and milder winters (IPCC, 2007), in which case we may hypothesize less pronounced seasonality in species diversity, as species live for longer portions of the year, and can generate phenological stretching (in contrast to phenological compression) (Craine et al. 2012). Indeed, we see that as the growing season is lengthened and temperature more constant from a to $\mathrm{b}$ to $\mathrm{c}$ in Fig. 3, we predict species to live for longer periods of the year and the species diversity to remain more constant. This prediction is supported by a study where we see that higher mean temperature and milder winters results in less pronounced seasonality in species diversity in flowering flora across three sites (Craine et al. 2012). Another prediction may be increasing bimodality. This prediction is supported by evidence from a montane meadow ecosystem (Aldridge et al. 2011).

Many phenological studies look at the beginning, or the first day a phenological event occurs and not the duration or end of activity of species. We examine the entire time period that the species are present. Very recent evidence (Cohen et al. 2018) found the peak abundance of some species tracked temperature more closely than other measures of phenology. That study also shows that smaller and ectothermic taxa track climate change with less delay than larger and endothermic taxa. We currently do not have the data to support a prediction such as the peak in species diversity is likely to occur earlier for animals found to be strongly responding to temperature change, i.e., terrestrial micro- and intermediate body-sized ectotherms in temperate and polar regions. Our analysis of eight terrestrial data sets from the northern hemisphere temperate region divided into exothermic intermediate body-sized organisms and endothermic macro body-sized organisms shows no clear trend to support this prediction (Appendix S1: Fig. S32). We do, however, think it is likely that SDRs track precipitation more closely in tropical than temperate zones so with changing precipitation regimes due to climate change, we may expect a bigger impact in tropical ecosystems (Cohen et al. 2018). This needs to be confirmed as a next step when we are able to assemble more SDRs and the corresponding environmental data. Direct species interactions are also obviously important so we also need to refine predictions on how consumer diversity should respond to resource diversity and vice versa in seasonal environments (Revilla et al. 2014). Clearly, in order to make predictions and address biodiversity conservation (Dawson et al. 2011), not only must ecosystem consequences (Loreau et al. 2001) and feedbacks (Chapin et al. 2000) be better understood, but seasonal patterns must be considered.

With this study, we have filled a gap in knowledge about ecological systems by providing data and modeling of worldwide seasonal patterns in diversity. Specifically, we have established a general SDR for many regions, habitats, and taxa. Additional effort should be put into documenting and explaining these patterns to further establish the global baseline. Although biodiversity data may be adequate for some temperate plants, we have poor coverage for most measures in space and time (Yoccoz et al. 2018) and with respect to the SDR, we would especially like to see more Arctic, southern hemisphere temperate, and Antarctic data. Once we have this temporal biodiversity data, we will be able to say if and how communities are changing (Chesson et al. 2004) and will change due to disrupted seasonality (Stevenson et al. 2015, Tonkin et al. 2017). Linking this change to other measures of seasonal ecosystem processes will be the next step.

\section{AcKNowledgments}

The authors would like to thank the Centre for Biodiversity Theory and Modeling (CBTM) lab members for helpful discussion and suggestions as well as Filippo Marolla and Tomàs Revilla and several reviewers, especially Jason Rohr and Ashley Asmus for constructive comments on the manuscript. Data were provided by the Greenland Ecosystem Monitoring Programme, as well as the LTER, and several generous researchers including S. Joseph Wright and Santiago Ramirez. J. Mellard designed the study, P. Audoye and J. Mellard collected data and performed meta-analyses, and J. Mellard permormed modeling work, J. Mellard wrote the first draft of the manuscript and M. Loreau contributed substantially to revisions. This work was supported by the TULIP Laboratory of Excellence (ANR-10LABX-41).

\section{Literature Cited}

Aldridge, G., D. W. Inouye, J. R. K. Forrest, W. A. Barr, and A. J. MillerRushing. 2011. Emergence of a midseason period of low floral resources in a montane meadow ecosystem associated with climate change. Journal of Ecology 99:905-913.

Ansari, Z. A., A. Chatterji, B. S. Ingole, R. A. Sreepada, C. U. Rivonkar, and A. H. Parulekar. 1995. Community structure and seasonal variation of an inshore demersal fish community at Goa, west coast of India. Estuarine, Coastal and Shelf Science 41:593-610.

Baker, K. K., and A. L. Baker. 1981. Seasonal succession of the phytoplankton in the upper Mississippi River. Hydrobiologia 83:295-301.

Barletta, M., A. Barletta-Bergan, U. Saint-Paul, and G. Hubold. 2003. Seasonal changes in density, biomass, and diversity of estuarine fishes in tidal mangrove creeks of the lower caeté estuary (northern Brazilian coast, east Amazon). Marine Ecology Progress Series 256:217-228.

Burkle, L., J. Marlin, and T. Knight. 2013. Plant-pollinator interactions over 120 years: loss of species, co-occurrence, and function. Science 339:1611-1615. 
Chapin, F. S. III, et al. 2000. Consequences of changing biodiversity. Nature 405:234-242.

Chase, J. M., and M. A. Leibold. 2003. Ecological niches: linking classical and contemporary approaches. The University of Chicago Press, Chicago, Illinois, USA.

Chesson, P., R. L. E. Gebauer, S. Schwinning, N. Huntly, K. Wiegand, M. S. K. Ernest, A. Sher, A. Novoplansky, and J. F. Weltzin. 2004. Resource pulses, species interactions, and diversity maintenance in arid and semi-arid environments. Oecologia 141:236-253.

Claridge, P. N., I. C. Potter, and M. W. Hardisty. 1986. Seasonal changes in movements, abundance, size composition and diversity of the fish fauna of the severn estuary. Journal of the Marine Biological Association of the United Kingdom 66:229-258.

Cohen, J. M., M. J. Lajeunesse, and J. R. Rohr. 2018. A global synthesis of animal phonological responses to climate change. Nature Climate Change 8:224-228.

Craine, J. M., E. M. Wolkovich, and E. G. Towne. 2012. The roles of shifting and filtering in generating communitylevel flowering phenology. Ecography 35:1033-1038.

Cushing, D. 1990. Plankton production and year-class strength in fish populations: an update of the match/mismatch hypothesis. Advances in Marine Biology 26:249-293.

Dawson, T. P., S. T. Jackson, J. I. House, I. C. Prentice, and G. M. Mace. 2011. Beyond predictions: Biodiversity conservation in a changing climate. Science 332:53-58.

Denlinger, D. L. 1980. Seasonal and annual variation of insect abundance in the Nairobi National Park, Kenya. Biotropica 12:100-106.

Devries, P. J., D. Murray, and R. Lande. 1997. Species diversity in vertical, horizontal, and temporal dimensions of a Fruitfeeding butterfly community in an Ecuadorian rainforest. Biological Journal of the Linnean Society 62:343-364.

Dillon, M. E., G. Wang, and R. B. Huey. 2010. Global metabolic impacts of recent climate warming. Nature 467:704 706.

Encinas-Viso, F., T. A. Revilla, and R. S. Etienne. 2012. Phenology drives mutualistic network structure and diversity. Ecology Letters 15:198-208.

Fischer, P., and R. Eckmann. 1997. Seasonal changes in fish abundance, biomass and species richness in the littoral zone of a large European lake, Lake Constance, Germany. Archiv für Hydrobiologie 139:433-448.

Fisher, R. A., A. S. Corbet, and C. B. Williams. 1943. The relation between the number of species 494 and the number of individuals in a random sample of an animal population. Journal of Animal Ecology 12:42-58.

Fitzgerald, L. A., F. B. Cruz, and G. Perotti. 1999. Phenology of a lizard assemblage in the dry chaco of argentina. Journal of Herpetology 33:526-535.

Fogden, M. P. L. 1972. The seasonality and population dynamics of equatorial forest birds EST Sarawak. Ibis 114: 307-343.

GEM. 2018. Greenland ecosystem monitoring programme, Nuuk ecological research operations. http://data.g-e-m.dk/

Hoff, J. G., and R. M. Ibara. 1977. Factors affecting the seasonal abundance, composition and diversity of fishes in a southeastern New England estuary. Estuarine and Coastal Marine Science 5:665-678.

Hsieh, C. H., K. Ishikawa, Y. Sakai, T. Ishikawa, S. Ichise, Y. Yamamoto, T. C. Kuo, H. D. Park, N. Yamamura, and M. Kumagai. 2010. Phytoplankton community reorganization driven by Eutrophication and warming in lake Biwa. Aquatic Sciences 72:467-483.

Inoue, T., M. Kato, T. Kakutani, T. Suka, and T. Itino. 1990. Insect-flower relationship in the temperate deciduous forest of Kibune, Kyoto: an overview of the flowering phenology and the seasonal pattern of insect visits. Contributions from the Biological Laboratory, Kyoto University 27:377-463.

IPCC. 2007. Climate Change 2007: Synthesis report. Contribution of working groups I, II and III to the fourth assessment report of the intergovernmental panel on climate change [Core writing team, Pachauri, R.K, and Reisinger, A. (eds.)]. IPCC, Geneva, Switzerland, 104 pp.

Irigoien, X., J. Huisman, and R. P. Harris. 2004. Global biodiversity patterns of marine phytoplankton and zooplankton. Nature 429:863-867.

Kharouba, H. M., J. Ehrlén, A. Gelman, K. Bolmgren, J. M. Allen, S. E. Travers, and E. M. Wolkovich. 2018. Global shifts in the phenological synchrony of species interactions over recent decades. Proceedings of the National Academy of Sciences of USA 115:5211-5216.

Klausmeier, C. A. 2010. Successional state dynamics: A novel approach to modelling nonequilibrium foodweb dynamics. Journal of Theoretical Biology 262:584-595.

Krasnov, B., and Y. Ayal. 1995. Seasonal changes in darkling beetle communities (Coleoptera: Tenebrionidae) in the Ramon erosion cirque, Negev highlands, Israel. Journal of Arid Environments 31:335-347.

Loreau, M.. 2010. From populations to ecosystems. Monographs in population biology. Princeton University Press, Princeton, New Jersy, USA.

Loreau, M., et al. 2001. Biodiversity and ecosystem functioning: Current knowledge and future challenges. Science 294:804-808.

Magurran, A. 2008. Diversity over time. Folia Geobot 43:319 327.

Mellard, J. P., C. de Mazancourt, and M. Loreau. 2015. Evolutionary responses to environmental change: trophic interactions affect adaptation and persistence. Proceedings of the Royal Society B Biological Sciences 282:1-8.

Moisan, J. R., T. A. Moisan, and M. R. Abbot. 2002. Modelling the effect of temperature on the maximum growth rates of phytoplankton populations. Ecological Modelling 153:197215.

Oertli, S., A. Mueller, and S. Dorn. 2005. Ecological and seasonal patterns in the diversity of a species-rich bee assemblage (Hymenoptera: Apoidea: Apiformes). European Journal of Entomology 102:53-63.

Owen, D. F. 1969. Species diversity and seasonal abundance in tropical sphingidae (lepidoptera). Physiological Entomology 44:162-168

Primo, A. L., U. M. Azeiteiro, S. C. Marques, F. Martinho, and M. A. Pardal. 2009. Changes in zooplankton diversity and distribution pattern under varying precipitation regimes in a southern temperate estuary. Estuarine, Coastal and Shelf Science 82:341-347.

Ramírez, S. R., C. Hernández, A. Link, and M. M. LópezUribe. 2015. Seasonal cycles, phylogenetic assembly, and functional diversity of orchid bee communities. Ecology and Evolution 5:1896-1907.

Revilla, T. A., F. Encinas-Viso, and M. Loreau. 2014. (A bit) earlier or later is always better: Phenological shifts in consumer-resource interactions. Theoretical Ecology 7:149-162.

Revilla, T. A., F. Encinas-Viso, and M. Loreau. 2015. Robustness of mutualistic networks under phenological change and habitat destruction. Oikos 124:22-32.

Rosenzweig, M. L. 1995. Species diversity in space and time. Cambridge University Press, Cambridge, UK.

Saenger, P., J. H. Moverley, and W. Stephenson. 1988. Seasonal and long-term patterns in the macrobenthos versus benthic stability in a subtropical estuary. Pages 229-237 in R. L. Kitching, editor. The Ecology of Australia's wet tropics: 
proceedings of Ecological Society of Australia symposium, vol. 15. University of Queensland, Brisbane, UK. Surrey Beatty and Sons for the Ecological Society of Australia.

Sala, O. E., et al. 2000. Global biodiversity scenarios for the year 2100. Science 287:1770-1774.

Scheffer, M., and E. van Nes. 2006. Self-organized similarity, the evolutionary emergence of groups of similar species. Proceedings of the National Academy of Sciences of USA 103:6230-6235.

Sewell, M. A., and J. A. Jury. 2011. Seasonal patterns in diversity and abundance of the high antarctic meroplankton: Plankton sampling using a ross sea desalination plant. Limnology and Oceanography 56:1667-1681.

Shaltout, K. H., and R. A. El Fahar. 1991. Diversity and phenology of weed communities in the nile delta region. Journal of Vegetation Science 2:385-390.

Sherry, R. A., X. Zhou, S. Gu, J. A. Arnone, D. S. Schimel, P. S. Verburg, L. L. Wallace, and Y. Luo. 2007. Divergence of reproductive phenology under climate warming. Proceedings of the National Academy of Sciences of USA 104:198-202.

Steiner, C. F., A. S. Schwaderer, V. Huber, C. A. Klausmeier, and E. Litchman. 2009. Periodically forced food-chain dynamics: model predictions and experimental validation. Ecology 90:3099-3107.

Stevenson, T. J., et al. 2015. Disrupted seasonal biology impacts health, food security and ecosystems. Proceedings of the Royal Society of London B: Biological Sciences 282:20151453.

Sunagawa, S., et al. 2015. Structure and function of the global ocean microbiome. Science 348:1261359.

Thompson, J. N., and M. F. Willson. 1979. Evolution of temperate fruit/bird interactions: phenological strategies. Evolution 33:973-982.

Tilman, D. 1977. Resource competition between planktonic algaeexperimental and theoretical approach. Ecology 58:338-348.

Tiple, A. D., and A. M. Khurad. 2009. Butterfly species diversity, habitats and seasonal distribution in and around nagpur city, central india. World Journal of Zoology 4:153-162.

Tondoh, J. E. 2006. Seasonal changes in earthworm diversity and community structure in central côte d'ivoire. European Journal of Soil Biology 42:S334-S340.

Tonkin, J. D., M. T. Bogan, N. Bonada, B. Rios-Touma, and D. A. Lytle. 2017. Seasonality and predictability shape temporal species diversity. Ecology 98:1201-1216.
Tremain, D. M., and D. H. Adams. 1995. Seasonal variations in species diversity, abundance, and composition of fish communities in the northern indian river lagoon, florida. Bulletin of Marine Science 57:171-192.

Trifonova, I. 1993. Intermediate Disturbance Hypothesis in Phytoplankton Ecology, chap. Seasonal succession of phytoplankton and its diversity in two highly eutrophic lakes with different conditions of stratification. Springer Netherlands, pp. 93-100.

Ulrich, W. 2005. The hymenoptera of a meadow on limestone: Ecological patterns of a local animal community. Forschungsbericht Zentrum für Waldschadensforschung 195:1203.

Usinowicz, J., et al. 2017. Temporal coexistence mechanisms contribute to the latitudinal gradient in forest diversity. Nature 550:105.

Weithoff, G., M. R. Rocha, and U. Gaedke. 2015. Comparing seasonal dynamics of functional and taxonomic diversity reveals the driving forces underlying phytoplankton community structure. Freshwater Biology 60:758-767.

Wetzel, R. G. 1975. Limnology. W.B. Saunders Company, Philadelphia.

White, E. P., et al. 2006. A comparison of the species-time relationship across ecosystems and taxonomic groups. Oikos 548:185-195.

Whitlatch, R. B. 1977. Seasonal changes in the community structure of the macrobenthos inhabiting the intertidal sand and mud flats of barnstable harbor, massachusetts. Biological Bulletin 152:275-294.

Wisheu, I. 1998. How organisms partition habitats: different types of communty organization can produce identical patterns. Oikos 83:246-258.

Wolkovich, E. M., and Cleland E. E. 2014. Phenological niches and the future of invaded ecosystems with climate change. AoB PLANTS 6:plu013.

Wright, S. J., and O. Calderon. 1995. Phylogenetic patterns among tropical flowering phenologies. Journal of Ecology 83:937-948.

Yoccoz, N. G., K. E. Ellingsen, and T. Tveraa. 2018. Biodiversity may wax or wane depending on metrics or taxa. Proceedings of the National Academy of Sciences of USA 115:1681-1683.

\title{
SUPPORTING INFORMATION
}

Additional supporting information may be found in the online version of this article at http://onlinelibrary.wiley.com/doi/ 10.1002/ecy.2627/suppinfo

\author{
Data Accessibility
}

Data used in analyses is available on Dryad https://doi.org/10.5061/dryad.r86c7f3 